\title{
3 Research Square \\ Clinical significance of conversion surgery for gastric cancer with peritoneal dissemination: A retrospective study
}

Takaaki Arigami ( $\boldsymbol{\nabla}$ arigami@m.kufm.kagoshima-u.ac.jp )

Kagoshima University Graduate School of Medical and Dental Sciences https://orcid.org/0000-0001-86508937

\section{Daisuke Matsushita}

Kagoshima University

Keishi Okubo

Kagoshima University

Takashi Kijima

Kagoshima University

Masataka Shimonosono

Kagoshima University

Ken Sasaki

Kagoshima University

Masahiro Noda

Kagoshima University

Yoshiaki Kita

Kagoshima University

Shinichiro Mori

Kagoshima University

Hiroshi Kurahara

Kagoshima University

Shigehiro Yanagita

Kagoshima University

Yoshikazu Uenosono

Kagoshima University

Sumiya Ishigami

Kagoshima University

Shoji Natsugoe

Kagoshima University

\section{Research article}

Keywords: conversion surgery, peritoneal dissemination, prognosis, gastric cancer 
Posted Date: May 7th, 2020

DOI: https://doi.org/10.21203/rs.3.rs-19825/v1

License: (9) (i) This work is licensed under a Creative Commons Attribution 4.0 International License. Read Full License

Version of Record: A version of this preprint was published at Oncology on January 1st, 2020. See the published version at https://doi.org/10.1159/000509530. 


\section{Abstract}

Background: Although chemotherapy has been clinically recommended as the initial treatment for patients with peritoneal dissemination of gastric cancer, poor prognosis has been noted among the same patients. However, the prognostic significance of conversion surgery after chemotherapy remains unclear. The present study therefore aimed to assess the clinical impact of conversion surgery among patients with peritoneal dissemination of gastric cancer.

Methods: A total of 93 patients with peritoneal dissemination of gastric cancer undergoing chemotherapy between February 2002 and October 2019 were retrospectively enrolled and subsequently divided into progressive disease (PD) and non-PD groups based on tumor response to chemotherapy.

Results: Among the included patients, 17 developed distant metastases at another site besides peritoneal dissemination. Based on tumor response, 24 and 69 patients were determined to have PD and non-PD, respectively, with the former having significantly poorer prognosis than the latter $(p<0.0001)$. A total of 19 patients underwent conversion surgery after chemotherapy, with the presence or absence of conversion surgery being significantly correlated with age, first-line chemotherapy regimen, and tumor response $(p=0.0134$, 0.0337 , and 0.0024 , respectively). Patients in the non-PD group who underwent conversion surgery or chemotherapy alone had 3-year overall survival rates of $55.6 \%$ and $6.6 \%$, respectively. Multivariate analysis identified conversion surgery alone as an independent prognostic factor in the non-PD group $(p<0.0001)$.

Conclusion: Our retrospective study demonstrated that conversion surgery for gastric cancer with peritoneal dissemination might improve the prognosis of responders who developed no peritoneal dissemination after chemotherapy.

\section{Background}

Gastric cancer is one of most common gastrointestinal malignancies in Asia and the third leading cause of cancer death worldwide [1]. Although recent developments in chemotherapy have considerably improved the prognosis of patients with unresectable advanced or recurrent gastric cancer, studies have reported a 8.8$14.9 \%$ 5-year survival rate among patients with stage IV disease [2, 3]. In particular, peritoneal dissemination has been one of the representative metastatic patterns among patients with advanced gastric cancer, with large type-3 and type-4 tumors frequently leading to peritoneal dissemination (P1) or positive peritoneal cytology (CY1) [4]. A retrospective study based on staging laparoscopy reported that $53.4 \%$ of patients with large type-3 and type-4 gastric cancer develop P1 or CY1 [4]. Reports have shown that patients with $\mathrm{CY} 1$ and P1 have a poor prognosis with a 5 -year overall survival (OS) rate of $12.3 \%$ and $8.3 \%$, respectively [5]. Currently, CY1 and P1 have been defined as distant metastasis (M1) in both the tumor-node-metastasis (TNM) classification for gastric carcinoma established by the International Union Against Cancer and the Japanese classification of gastric carcinoma [6, 7]. Consequently, gastric cancer with $\mathrm{CY} 1$ or P1 are classified into stage IV $[6,7]$. The aforementioned findings demonstrate that peritoneal dissemination is one of the most important prognostic factors among patients with gastric cancer.

The Japanese Gastric Cancer Treatment Guidelines 2018 recommends systemic chemotherapy as the standard first-line treatment among patients with M1 gastric cancer, including peritoneal dissemination [8]. 
Recently, Yoshida et al. proposed a new biological classification for the therapeutic guidance of patients with stage IV gastric cancer [9]. This new classification categorizes patients with stage IV gastric cancer into four groups (categories 1-4), with those having P1 belonging to category 3 or 4 [9]. Moreover, the therapeutic strategy of patients with various malignancies, including gastric cancer, focuses on conversion therapy based on the concept that patients with category 3 and 4 can achieve curative resection (R0) following the surgery [9].

To date, several investigators have reported the clinical utility of conversion surgery after chemotherapy among patients with colorectal, pancreatic, esophageal, and gastric cancer [10-13]. Unfortunately, only a few studies have been conducted on conversion surgery among responders with P1 gastric cancer after chemotherapy [14-16]. Hence, the clinical impact of conversion surgery remains unclear among patients with peritoneal dissemination of gastric cancer.

The present study therefore aimed to investigate tumor response and the presence or absence of conversion surgery among patients with P1 gastric cancer and evaluate the relationship between tumor response and conversion surgery. Furthermore, the study assessed the prognostic significance of conversion surgery as a promising therapeutic strategy among chemotherapy responders.

\section{Methods}

\section{Patients}

We retrospectively reviewed 93 patients (55 men and 38 women; age range, 30-86 years; mean age, 64.2 years) with peritoneal dissemination of gastric cancer who underwent chemotherapy at Kagoshima University Hospital (Kagoshima, Japan) between February 2002 and October 2019. Patients with synchronous or metachronous cancer in other organs and disease recurrence were excluded from the present study. All patients underwent blood examinations, esophagogastroduodenoscopy, endoscopic ultrasonography, fluoroscopy, and computed tomography before starting chemotherapy. Patients were categorized and staged based on the TNM classification for gastric carcinoma [7]. Table 1 shows the clinicopathological features of patients enrolled herein. Among the 93 patients identified, 5 and 88 had T3 and T4 tumors, respectively. Lymph node metastasis was clinically detected in 70 patients, while 18, 27, and 25 patients had N1, N2, and N3 nodal status, respectively. Furthermore, 76 patients had peritoneal dissemination alone, while 17 had more than two distant metastatic sites, including peritoneal dissemination. Among the 17 patients with more than two distant metastatic sites, 5, 12, 1, and 1 had liver metastasis, distant lymph node metastasis, ovarian metastasis, and bone metastasis, respectively. This retrospective observational study was approved by the Ethics Committee of Kagoshima University. 
Table 1

Clinicopathological features $(n=93)$

\begin{tabular}{|c|c|}
\hline Factor & $\mathrm{n}(\%)$ \\
\hline \multicolumn{2}{|l|}{ Gender } \\
\hline Male & $55(59.1)$ \\
\hline Female & $38(40.9)$ \\
\hline Age (years, range) & $64.2(30-86)$ \\
\hline \multicolumn{2}{|l|}{ Tumor location } \\
\hline Whole & $27(29.0)$ \\
\hline Upper & $27(29.0)$ \\
\hline Middle & $20(21.5)$ \\
\hline Lower & $19(20.4)$ \\
\hline \multicolumn{2}{|l|}{ Macroscopic type } \\
\hline Type 1 & $2(2.2)$ \\
\hline Type 2 & $2(2.2)$ \\
\hline Type 3 & $42(45.2)$ \\
\hline Type 4 & $46(49.5)$ \\
\hline Type 5 & $1(1.1)$ \\
\hline \multicolumn{2}{|l|}{ Depth of tumor invasion } \\
\hline cT3 & $5(5.4)$ \\
\hline cT4 & $88(94.6)$ \\
\hline \multicolumn{2}{|l|}{ Lymph node metastasis } \\
\hline cNO & $23(24.7)$ \\
\hline cN1 & $18(19.4)$ \\
\hline cN2 & $27(29.0)$ \\
\hline cN3 & $25(26.9)$ \\
\hline \multicolumn{2}{|l|}{ Number of distant metastatic sites } \\
\hline 1 (peritoneal dissemination alone) & $76(81.7)$ \\
\hline$\geq 2$ & $17(18.3)$ \\
\hline \multicolumn{2}{|l|}{ Histological type } \\
\hline Differentiated & $15(16.1)$ \\
\hline
\end{tabular}




\begin{tabular}{|ll|}
\hline Factor & $\mathbf{n}(\%)$ \\
\hline Undifferentiated & $78(83.9)$ \\
\hline First-line chemotherapy regimen & \\
\hline Platinum-based chemotherapy & $56(60.2)$ \\
\hline Taxane-based chemotherapy & $37(39.8)$ \\
\hline
\end{tabular}

\section{Chemotherapy And Assessment Of Tumor Response}

Among the 93 patients included herein, 56 and 37 received platinum-based and taxane-based chemotherapy, including intraperitoneal paclitaxel therapy, as their first-line regimen, respectively. Moreover, 16 patients with human epidermal growth factor receptor 2-positive gastric cancer received trastuzumab combined with chemotherapy. Tumor response was determined every three chemotherapy cycles and was evaluated using the Response Evaluation Criteria in Solid Tumors (RECIST) [17]. The present study classified tumor response into the following two groups: progressive disease (PD) and non-PD. Survival time was defined as the duration from chemotherapy initiation to death or last follow-up.

\section{Conversion Surgery}

Conversion surgery was clinically indicated for patients with a performance status of at least $0-2$, non-PD after chemotherapy, and tumors determined to fulfill curative R0 resection. Therefore, patients underwent staging laparotomy or laparoscopy before conversion surgery. Those who had tumors with non-curative factors, such as $\mathrm{P} 1$ and $\mathrm{CY} 1$, during staging laparotomy or laparoscopy were not considered for conversion surgery.

\section{Assessment Of Pathological Treatments In Resected Specimens}

Tumor specimens resected following conversion surgery were pathologically examined, after which appropriate therapeutic responses were determined according to the Japanese classification of gastric carcinoma [6]. Surgical resection was classified into R0, R1, and R2 based on the presence or absence of residual tumors after conversion surgery, while the histological response of primary tumors was categorized into grades $0,1 a, 1 b, 2$, and 3 .

\section{Statistical analysis}

The relationship between the presence or absence of conversion surgery and categorical clinicopathological factors, including tumor response, was determined using the chi-square test, Fisher's exact test, or Wilcoxon rank-sum test. Kaplan-Meier survival curves were generated, after which prognostic differences were determined using the log-rank test. Prognostic factors were determined using univariate and multivariate 
analyses (Cox proportional hazards regression modeling). All data were analyzed using SAS statistical software (SAS Institute Inc., Cary, NC, USA), with a value of $p<0.05$ being considered statistically significant.

\section{Results}

\section{Tumor response and prognosis after chemotherapy}

Based on the RECIST, 24 and 69 patients had PD and non-PD, respectively. Accordingly, the disease control rate was $74.2 \%$ (69/93), while the median survival times of patients with PD and non-PD were 163 and 562 days, respectively (Fig. 1), the difference therein being statistically significant $(p<0.0001)$.

\section{Conversion Surgery And Pathological Findings}

Among the 93 patients included herein, 19 (20.4\%) underwent gastrectomy with lymphadenectomy as conversion surgery after chemotherapy. Surgical and pathological findings are summarized in Table 2. Distal gastrectomy and total gastrectomy were performed in 3 and 16 patients, while D1+, D2, and D2 + lymphadenectomy was performed in 5, 12, and 2 patients, respectively. Although 18 patients achieved R0 resection, one developed occult metastasis identified during pathological examinations of the greater omentum. Moreover, nine, three, one, and six patients had a pathological nodal status of N0, N1, N2, and N3, respectively. Histological assessment revealed 15, 2, and 2 patients with grade $1 \mathrm{a}, 1 \mathrm{~b}$, and 2 tumor response, respectively, with no patient exhibiting grade 3 response. 
Table 2

Surgical and pathological findings of patients undergoing conversion surgery $(n=$ 19)

\begin{tabular}{|c|c|}
\hline Factor & $\mathrm{n}(\%)$ \\
\hline \multicolumn{2}{|l|}{ Operative procedure } \\
\hline Total gastrectomy & $16(84.2)$ \\
\hline Distal gastrectomy & $3(15.8)$ \\
\hline \multicolumn{2}{|c|}{ Lymph node dissection } \\
\hline D1+ & $5(26.3)$ \\
\hline D2 & $12(63.2)$ \\
\hline D2+ & $2(10.5)$ \\
\hline \multicolumn{2}{|c|}{ Depth of tumor invasion } \\
\hline \multicolumn{2}{|l|}{ pT1 } \\
\hline pT2 & $2(10.5)$ \\
\hline pT3 & $10(52.6)$ \\
\hline pT4 & $7(36.8)$ \\
\hline \multicolumn{2}{|c|}{ Lymph node metastasis } \\
\hline pNO & $9(47.4)$ \\
\hline pN1 & $3(15.8)$ \\
\hline pN2 & $1(5.3)$ \\
\hline pN3 & $6(31.6)$ \\
\hline \multicolumn{2}{|c|}{ Residual tumor status } \\
\hline Ro & $18(94.7)$ \\
\hline $\mathrm{R} 1$ & $1(5.3)$ \\
\hline $\mathrm{R} 2$ & $0(0.0)$ \\
\hline \multicolumn{2}{|c|}{ Histological response } \\
\hline Grade 1a & $15(78.9)$ \\
\hline Grade 1b & $2(10.5)$ \\
\hline Grade 2 & $2(10.5)$ \\
\hline Grade 3 & 0 \\
\hline
\end{tabular}




\section{Relationship Between Conversion Surgery And Clinicopathological Findings}

The mean age ( \pm standard deviation) of the 19 and 74 patients who underwent conversion surgery and chemotherapy alone was $57.6 \pm 12.2$ and $65.9 \pm 11.5$ years, respectively (Table 3 ). Accordingly, we determined that the presence or absence of conversion surgery was significantly correlated with age $(p=0.0134)$. Among the 37 patients receiving taxane-based chemotherapy, 12 (32.4\%) underwent conversion surgery. On the other hand, among 56 patients receiving platinum-based chemotherapy, 7 (12.5\%) underwent conversion surgery. Accordingly, we determined that conversion surgery was significantly associated with the first-line regimen ( $p=$ 0.0337) (Table 3). Furthermore, among the 69 patients with non-PD, 19 (27.5\%) underwent conversion surgery. None of the patients who underwent conversion surgery had PD. Accordingly, we determined that conversion surgery was significantly correlated with tumor response $(p=0.0024)$ (Table 3$)$. 
Table 3

Relationship between conversion surgery and clinicopathological findings $(n=93)$

\section{Treatments (\%)}

Factor

Gender

Male

Female

Age (years)

Tumor location

Whole/Upper

Middle/Lower

Macroscopic type

Type non-T4

Type 4

Depth of tumor invasion

cT3

cT4

Lymph node metastasis

$\mathrm{cNO}-1$

cN2-3

Number of distant metastatic sites

1 (peritoneal dissemination alone)

$\geq 2$

Histological type

Differentiated

Undifferentiated

$12(29.3)$

$7(13.5)$

$29(70.7)$

$45(86.5)$

Conversion surgery (n

=19)

$12(21.8)$

7 (18.4)

$57.6 \pm 12.2$

$12(22.2)$

7 (18.0)

$11(23.4)$

8 (17.4)

$1(20.0)$

$18(20.5)$

$4(80.0)$

$70(79.6)$

Chemotherapy alone ( $\mathrm{n}$

=74)

$p$ value

0.7965

43 (78.2)

$31(81.6)$

$65.9 \pm 11.5$

0.0134

0.7951

42 (77.8)

$32(82.1)$

$36(76.6)$

$38(82.6)$

1.0000

0.0734

$18(23.7)$

$1(5.9)$

$16(94.1)$

$58(76.3)$

$6(94.1)$

12 (80.0)

62 (79.5)

First-line chemotherapy regimen

Platinum-based chemotherapy 


\section{Treatments (\%)}

Tumor response to chemotherapy

PD

$0(0.0)$

$24(100.0)$

Non-PD

$19(27.5)$

$50(72.5)$

$P D$ progressive disease

\section{Prognostic Analysis In Both The Non-pd And Pd Groups}

Among all included patients $(n=93)$, those who underwent conversion surgery and chemotherapy alone had a 3 -year OS rate of $55.6 \%$ and $4.2 \%$, respectively $(p<0.0001)$ (Fig. 2$)$.

Univariate analysis indicated that lymph node metastasis status (N0-1 vs. N2-3), number of distant metastatic sites ( $1 \mathrm{vs} . \geq 2$ ), tumor response, and conversion surgery were significantly correlated with survival among patients with non-PD and $\mathrm{PD}(p=0.0156, p=0.0081, p<0.0001$, and $p<0.0001$, respectively) (Table 4).

Multivariate analysis further identified the number of distant metastatic sites ( $1 \mathrm{vs} . \geq 2)$, tumor response, and conversion surgery as independent prognostic factors $(p=0.0092, p<0.0001$, and $p<0.0001$, respectively) (Table 4). 
Table 4

Univariate and multivariate analyses of survival in both the progressive and non-progressive disease groups ( $\mathrm{n}$ $=93$ )

\begin{tabular}{|c|c|c|c|c|c|c|}
\hline \multirow[b]{2}{*}{$\begin{array}{l}\text { Independent } \\
\text { factor }\end{array}$} & \multicolumn{3}{|c|}{ Univariate analysis } & \multicolumn{3}{|c|}{ Multivariate analysis } \\
\hline & $\begin{array}{l}\text { Hazard } \\
\text { ratio }\end{array}$ & $95 \% \mathrm{Cl}$ & $\begin{array}{l}p \\
\text { value }\end{array}$ & $\begin{array}{l}\text { Hazard } \\
\text { ratio }\end{array}$ & $95 \% \mathrm{Cl}$ & $\begin{array}{l}p \\
\text { value }\end{array}$ \\
\hline Gender & & & 0.1585 & & & \\
\hline Female & 1.000 & reference & & & & \\
\hline Male & 1.384 & $\begin{array}{l}0.881- \\
2.191\end{array}$ & & & & \\
\hline Age (years) & & & 0.1306 & & & \\
\hline$<60$ & 1.000 & reference & & & & \\
\hline$\geq 60$ & 1.446 & $\begin{array}{l}0.899- \\
2.395\end{array}$ & & & & \\
\hline Tumor location & & & 0.3623 & & & \\
\hline Whole/Upper & 1.000 & reference & & & & \\
\hline Middle/Lower & 1.239 & $\begin{array}{l}0.777- \\
1.954\end{array}$ & & & & \\
\hline $\begin{array}{l}\text { Macroscopic } \\
\text { type }\end{array}$ & & & 0.3696 & & & \\
\hline Type non-T4 & 1.000 & reference & & & & \\
\hline Type 4 & 0.812 & $\begin{array}{l}0.516- \\
1.284\end{array}$ & & & & \\
\hline $\begin{array}{l}\text { Depth of tumor } \\
\text { invasion }\end{array}$ & & & 0.6592 & & & \\
\hline cT3 & 1.000 & reference & & & & \\
\hline cT4 & 1.248 & $\begin{array}{l}0.513- \\
4.121\end{array}$ & & & & \\
\hline $\begin{array}{l}\text { Lymph node } \\
\text { metastasis }\end{array}$ & & & 0.0156 & & & 0.6698 \\
\hline $\mathrm{cNO}-1$ & 1.000 & reference & & 1.000 & reference & \\
\hline $\mathrm{cN} 2-3$ & 1.757 & $\begin{array}{l}1.112- \\
2.811\end{array}$ & & 1.113 & $\begin{array}{l}0.681- \\
1.836\end{array}$ & \\
\hline $\begin{array}{l}\text { Number of } \\
\text { distant } \\
\text { metastatic sites }\end{array}$ & & & 0.0081 & & & 0.0092 \\
\hline $\begin{array}{l}1 \text { (peritoneal } \\
\text { dissemination } \\
\text { alone) }\end{array}$ & 1.000 & reference & & 1.000 & reference & \\
\hline
\end{tabular}




\begin{tabular}{|c|c|c|c|c|c|c|}
\hline \multirow[b]{2}{*}{$\geq 2$} & \multicolumn{3}{|c|}{ Univariate analysis } & \multicolumn{3}{|c|}{ Multivariate analysis } \\
\hline & 2.382 & $\begin{array}{l}1.269- \\
4.238\end{array}$ & & 2.410 & $\begin{array}{l}1.258- \\
4.403\end{array}$ & \\
\hline $\begin{array}{l}\text { Histological } \\
\text { type }\end{array}$ & & & 0.4435 & & & \\
\hline Differentiated & 1.000 & reference & & & & \\
\hline Undifferentiated & 1.291 & $\begin{array}{l}0.690- \\
2.693\end{array}$ & & & & \\
\hline $\begin{array}{l}\text { First-line } \\
\text { chemotherapy } \\
\text { regimen }\end{array}$ & & & 0.8917 & & & \\
\hline $\begin{array}{l}\text { Platinum-based } \\
\text { chemotherapy }\end{array}$ & 1.000 & reference & & & & \\
\hline $\begin{array}{l}\text { Taxane-based } \\
\text { chemotherapy }\end{array}$ & 0.969 & $\begin{array}{l}0.610- \\
1.528\end{array}$ & & & & \\
\hline $\begin{array}{l}\text { Tumor response } \\
\text { to } \\
\text { chemotherapy }\end{array}$ & & & $\begin{array}{l}< \\
0.0001\end{array}$ & & & $<0001$ \\
\hline Non-PD & 1.000 & reference & & 1.000 & reference & \\
\hline PD & 5.793 & $\begin{array}{l}3.330- \\
9.922\end{array}$ & & 4.559 & $\begin{array}{l}2.530- \\
8.176\end{array}$ & \\
\hline $\begin{array}{l}\text { Conversion } \\
\text { surgery }\end{array}$ & & & $\hat{0}_{0.0001}$ & & & $\overleftarrow{0}_{0.0001}^{<}$ \\
\hline Absence & 1.000 & reference & & 1.000 & reference & \\
\hline Presence & 0.177 & $\begin{array}{l}0.082- \\
0.347\end{array}$ & & 0.234 & $\begin{array}{l}0.105- \\
0.482\end{array}$ & \\
\hline $\begin{array}{l}\text { C/confidence inte } \\
\text { progressive disea }\end{array}$ & & & & & & \\
\hline
\end{tabular}

\section{Prognostic Analysis In The Non-pd Group Alone}

Among patients in the non-PD group $(n=69)$, those who underwent conversion surgery and chemotherapy alone had a 3-year OS rate of $55.6 \%$ and $6.6 \%$, respectively $(p<0.0001)$ (Fig. 3).

Univariate analysis showed that lymph node metastasis status (N0-1 vs. N2-3), number of distant metastatic sites (1 vs. $\geq 2$ ), histological type, and conversion surgery were significantly associated survival in the non-PD group ( $p=0.0224, p=0.0092, p=0.0338$, and $p<0.0001$, respectively) (Table 5). Multivariate analysis further identified conversion surgery alone as a significant independent predictor of a favorable survival $(p<0.0001)$ (Table 5). 
Table 5

Univariate and multivariate analyses of survival in the non-progressive disease group alone $(n=69)$

\begin{tabular}{|c|c|c|c|c|c|c|}
\hline \multirow[b]{2}{*}{$\begin{array}{l}\text { Independent } \\
\text { factor }\end{array}$} & \multicolumn{3}{|c|}{ Univariate analysis } & \multicolumn{3}{|c|}{ Multivariate analysis } \\
\hline & $\begin{array}{l}\text { Hazard } \\
\text { ratio }\end{array}$ & $95 \% \mathrm{Cl}$ & $\begin{array}{l}p \\
\text { value }\end{array}$ & $\begin{array}{l}\text { Hazard } \\
\text { ratio }\end{array}$ & $95 \% \mathrm{Cl}$ & $\begin{array}{l}p \\
\text { value }\end{array}$ \\
\hline Gender & & & 0.5799 & & & \\
\hline Female & 1.000 & reference & & & & \\
\hline Male & 1.166 & $\begin{array}{l}0.674- \\
2.006\end{array}$ & & & & \\
\hline Age (years) & & & 0.7465 & & & \\
\hline$<60$ & 1.000 & reference & & & & \\
\hline$\geq 60$ & 1.095 & $\begin{array}{l}0.633- \\
1.926\end{array}$ & & & & \\
\hline Tumor location & & & 0.2725 & & & \\
\hline Whole/Upper & 1.000 & reference & & & & \\
\hline Middle/Lower & 1.366 & $\begin{array}{l}0.778- \\
2.358\end{array}$ & & & & \\
\hline $\begin{array}{l}\text { Macroscopic } \\
\text { type }\end{array}$ & & & 0.3455 & & & \\
\hline Type non-T4 & 1.000 & reference & & & & \\
\hline Type 4 & 0.768 & $\begin{array}{l}0.444- \\
1.335\end{array}$ & & & & \\
\hline $\begin{array}{l}\text { Depth of tumor } \\
\text { invasion }\end{array}$ & & & 0.3063 & & & \\
\hline сT3 & 1.000 & reference & & & & \\
\hline cT4 & 1.954 & $\begin{array}{l}0.599- \\
12.023\end{array}$ & & & & \\
\hline $\begin{array}{l}\text { Lymph node } \\
\text { metastasis }\end{array}$ & & & 0.0224 & & & 0.0859 \\
\hline cNO-1 & 1.000 & reference & & 1.000 & reference & \\
\hline cN2-3 & 1.888 & $\begin{array}{l}1.095- \\
3.300\end{array}$ & & 1.637 & $\begin{array}{l}0.933- \\
2.903\end{array}$ & \\
\hline $\begin{array}{l}\text { Number of } \\
\text { distant } \\
\text { metastatic sites }\end{array}$ & & & 0.0092 & & & 0.1086 \\
\hline $\begin{array}{l}1 \text { (peritoneal } \\
\text { dissemination } \\
\text { alone) }\end{array}$ & 1.000 & reference & & 1.000 & reference & \\
\hline
\end{tabular}




\begin{tabular}{|c|c|c|c|c|c|c|}
\hline \multirow[b]{2}{*}{$\geq 2$} & \multicolumn{3}{|c|}{ Univariate analysis } & \multicolumn{3}{|c|}{ Multivariate analysis } \\
\hline & 2.953 & $\begin{array}{l}1.332- \\
6.095\end{array}$ & & 1.932 & $\begin{array}{l}0.856- \\
4.073\end{array}$ & \\
\hline $\begin{array}{l}\text { Histological } \\
\text { type }\end{array}$ & & & 0.0338 & & & 0.0581 \\
\hline Differentiated & 1.000 & reference & & 1.000 & reference & \\
\hline Undifferentiated & 2.656 & $\begin{array}{l}1.069- \\
8.873\end{array}$ & & 2.454 & $\begin{array}{l}0.973- \\
8.266\end{array}$ & \\
\hline $\begin{array}{l}\text { First-line } \\
\text { chemotherapy } \\
\text { regimen }\end{array}$ & & & 0.3648 & & & \\
\hline $\begin{array}{l}\text { Platinum-based } \\
\text { chemotherapy }\end{array}$ & 1.000 & reference & & & & \\
\hline $\begin{array}{l}\text { Taxane-based } \\
\text { chemotherapy }\end{array}$ & 0.774 & $\begin{array}{l}0.440- \\
1.345\end{array}$ & & & & \\
\hline $\begin{array}{l}\text { Conversion } \\
\text { surgery }\end{array}$ & & & $\begin{array}{l}< \\
0.0001\end{array}$ & & & $<.0001$ \\
\hline Absence & 1.000 & reference & & 1.000 & reference & \\
\hline Presence & 0.212 & $\begin{array}{l}0.096- \\
0.429\end{array}$ & & 0.243 & $\begin{array}{l}0.109- \\
0.503\end{array}$ & \\
\hline $\begin{array}{l}\mathrm{Cl} \text { confidence inte } \\
\text { progressive disea }\end{array}$ & & & & & & \\
\hline
\end{tabular}

\section{Discussion}

Although patients with P1 gastric cancer conventionally undergo gastrectomy with lymphadenectomy, chemotherapy has recently been proposed as the initial treatment given the remarkable progress in cytotoxic drugs, molecular targeted drugs, and immune checkpoint inhibitors [8]. Moreover, while conversion surgery has currently been proposed for responders to chemotherapy [9], little is understood about the clinical indications and prognostic impact of surgical interventions after chemotherapy among patients with P1 gastric cancer. Therefore, the current study retrospectively examined the clinical data of patients with P1 who underwent chemotherapy and assessed the clinical significance of conversion surgery after chemotherapy.

Surprisingly, the present study found that $94.7 \%$ of patients with P1 had type 3 or type 4 tumors. Moreover, all patients who had type 3 and type 4 tumors and no clinical P1 determined through imaging examinations underwent staging laparoscopy. Furthermore, $\mathrm{PO}$ and $\mathrm{CYO}$ in all patients undergoing conversion surgery were confirmed through staging laparoscopy or laparotomy. Such findings indicated that staging laparoscopy was clinically useful for identifying occult peritoneal dissemination among patients with large type 3 and type 4 tumors. In the near future, staging laparoscopy may become an essential tool for determining therapeutic strategies among patients with P1 gastric cancer. 
The present study found that chemotherapy induced a disease control rate of $74.2 \%$ (69/93). Moreover, our results showed that patients with PD had a significantly poorer prognosis than those with non-PD, with multivariate analysis identifying tumor response as an independent prognostic factor. These results suggested that the strategic management of patients with P1 gastric cancer should aim for good tumor response based on a high chemosensitivity. The present study also showed a close relationship between the presence of conversion surgery and taxane-based chemotherapy. Among the 93 patients included herein, 14 and 11 received intraperitoneal paclitaxel plus systemic chemotherapy as their first- and second- or later-line treatment, respectively. Accordingly, we found that patients receiving at least intraperitoneal paclitaxel therapy significantly outnumbered those not receiving the same $(p=0.0399$, data not shown). A randomized phase III trial comparing intraperitoneal and intravenous paclitaxel plus S-1 (IP) and S-1 plus cisplatin (SP) among patients with P1 gastric cancer showed median survival times of 17.7 and 15.2 months and 3-year OS rates of 21.9\% and 6.0\% for the IP and SP arms, respectively [18]. These findings suggested that intraperitoneal paclitaxel therapy better controlled peritoneal dissemination among patients with advanced gastric cancer compared to S-1 plus cisplatin. Consequently, intraperitoneal chemotherapy might be a promising therapeutic strategy for patients with P1 gastric cancer.

The Japanese classification of gastric carcinoma categorizes the histological response of primary tumors into four grades, with grade 3 indicating the absence of viable tumor cells [6]. Nakamura et al. reported that 5.9\% of patients with P1 or CY1 gastric cancer undergoing conversion surgery after chemotherapy exhibited grade 3 response [15]. Similarly, Kinoshita et al. reported that among 34 patients with stage IV gastric cancer who underwent conversion surgery following docetaxel, cisplatin, and S-1 therapy, only 2 (5.9\%) displayed grade 3 histological response [19]. In the present study, however, none of the patients exhibited grade 3 histological response. The aforementioned findings suggest the difficultly of completely eradicating primary gastric tumor cells through chemotherapy. Considering that conversion surgery after chemotherapy allows for the removal of viable tumor cells in primary sites and lymph nodes, its clinical advantage may lie in its ability to eliminate chemoresistant tumor cells.

Clinical indications for conversion surgery after chemotherapy among in patients with P1 gastric cancer have remained uncertain. However, recent studies have demonstrated the clinical importance of R0 resection in conversion surgery [20-22]. Fukuchi et al. reported that patients with unresectable gastric cancer undergoing $\mathrm{R} 0$ and R1/R2 resections had a 5 -year OS rates of $49 \%$ and $15 \%$, respectively [20]. Furthermore, the same study identified $\mathrm{RO}$ resection as an independent predictor for a favorable OS after multivariate analysis [20]. An Italian retrospective cohort study also identified residual tumor status after conversion surgery (R0 vs. R1) as an independent prognostic factor for progression-free survival among patients with stage IV unresectable gastric cancer following multivariate analysis [22]. The present study obtained an R0 resection rate of 94.7\% (18/19). Hence, responders confirmed to have PO and CYO after staging laparoscopy during chemotherapy may at least be clinically indicated for conversion surgery. Moreover, univariate analysis among responders indicated a close relationship between survival and lymph node status, number of distant metastatic sites, or histological type. The aforementioned clinicopathological factors might become important predictors for determining indications for conversion surgery. Furthermore, multivariate analysis identified conversion surgery as an independent prognostic factor among responders. Several studies among patients with PO and CY1 gastric cancer have showed that those who underwent conversion surgery had significantly better prognosis than

Page 16/22 
those who did not receive surgical treatments $[15,16]$. Therefore, conversion surgery could potentially improve the clinical prognosis after chemotherapy among patients with $\mathrm{P} 1$ gastric cancer.

Several limitations of the present study are worth noting. First, this was a single-center retrospective study including only on a small population $(n=93)$. Second, varying chemotherapy regimens had been included considering the patient's conditions or physician's discretion. These limitations might have resulted in bias that could have impacted our results. Accordingly, larger prospective studies would be needed to validate our conclusions.

\section{Conclusion}

The present study suggested that conversion surgery for $\mathrm{P} 1$ gastric cancer might be a promising strategy for considerably improving the prognosis of responders with $\mathrm{PO}$ and $\mathrm{CYO}$ after chemotherapy.

\section{Abbreviations}

IP: intraperitoneal and intravenous paclitaxel plus S-1; OS: overall survival; PD: Progressive disease; RECIST: Response Evaluation Criteria in Solid Tumors; SP: S-1 plus cisplatin; TNM: tumor-node-metastasis

\section{Declarations}

\section{Ethics approval and consent to participate}

This retrospective observational study was approved by the Ethics Committee of the Kagoshima University. All patients provided written informed consent to the use and publication of their information.

\section{Consent for publication}

Not applicable.

\section{Availability of data and materials}

The datasets used and/or analyzed during the current study are available from the corresponding author on reasonable request.

\section{Competing interests}

The authors declare that they have no competing interests.

\section{Funding}

No funding.

\section{Authors' contributions}

TA, DM, KO, TK, MS, KS, MN, YK, SM, HK, SY, YU, SI and SN participated in the study design. TA, DM, KO, TK, MS, KS and MN were involved in data collection and data interpretation. YK, SM, HK, SY, YU, SI and SN participated 
in the statistical analyses. TA wrote the manuscript. All authors read and approved the final manuscript.

\section{Acknowledgements}

No acknowledgements.

\section{References}

1. Fock KM. Review article: the epidemiology and prevention of gastric cancer. Aliment Pharmacol Ther. 2014;40:250-60.

2. Nashimoto A, Akazawa K, Isobe Y, Miyashiro I, Katai H, Kodera Y, Tsujitani S, Seto Y, Furukawa H, Oda I, Ono H, Tanabe S, Kaminishi M. Gastric cancer treated in 2002 in Japan: 2009 annual report of the JGCA nationwide registry. Gastric Cancer. 2013;16:1-27.

3. Kim SG, Seo HS, Lee HH, Song KY, Park CH. Comparison of the Differences in Survival Rates between the 7th and 8th Editions of the AJCC TNM Staging System for Gastric Adenocarcinoma: a Single-Institution Study of 5,507 Patients in Korea. J Gastric Cancer. 2017;17:212-9.

4. Miki Y, Tokunaga M, Tanizawa Y, Bando E, Kawamura T, Terashima M. Staging Laparoscopy for Patients with cM0, Type 4, and Large Type 3 Gastric Cancer. World J Surg. 2015;39:2742-

5. Nashimoto A, Akazawa K, Isobe Y, Miyashiro I, Katai H, Kodera Y, Tsujitani S, Seto Y, Furukawa H, Oda I, Ono H, Tanabe S, Kaminishi M. Gastric cancer treated in 2002 in Japan: 2009 annual report of the JGCA nationwide registry. Gastric Cancer. 2013;16:1-

6. Japanese Gastric Cancer Association. Japanese classification of gastric carcinoma: 3rd English edition. Gastric Cancer. 2011;14:101-

7. Amin MB, Edge S, Greene F, Byrd DR, Brookland RK, Washington MK, Gershenwald JE, Compton CC, Hess KR, Sullivan DC, Jessup JM, Brierley JD, Gaspar LE, Schilsky RL, Balch CM, Winchester DP, Asare EA, Madera M, Gress DM, Meyer LR, eds. AJCC Cancer Staging Manual, 8th edn. New York, NY: Springer; 2017.

8. Japanese Gastric Cancer Japanese gastric cancer treatment guidelines 2018 (5th edition). Gastric Cancer, 2020. doi: 10.1007/s10120-020-01042-y.

9. Yoshida K, Yamaguchi K, Okumura N, Tanahashi T, Kodera Y. Is conversion therapy possible in stage IV gastric cancer: the proposal of new biological categories of classification. Gastric Cancer. 2016;19:32938.

10. Adam R, Wicherts DA, de Haas RJ, Ciacio O, Lévi F, Paule B, Ducreux M, Azoulay D, Bismuth H, Castaing D. Patients with initially unresectable colorectal liver metastases: is there a possibility of cure? J Clin Oncol. 2009;27:1829-

11. Makino T, Yamasaki M, Tanaka K, Miyazaki Y, Takahashi T, Kurokawa Y, Motoori M, Kimura Y, Nakajima K, Mori M, Doki Y. Treatment and clinical outcome of clinical T4 esophageal cancer: A systematic review. Ann Gastroenterol Surg. 2018;3:169-

12. Satoi S, Yamamoto T, Yamaki S, Sakaguchi T, Sekimoto M. Surgical indication for and desirable outcomes of conversion surgery in patients with initially unresectable pancreatic ductal adenocarcinoma. Ann Gastroenterol Surg. 2019;4:6- 
13. Arigami T, Matsushita D, Okubo K, Kawasaki Y, lino S, Sasaki K, Noda M, Kita Y, Mori S, Kurahara H, Maemura K, Yanagita S, Uenosono Y, Ishigami S, Natsugoe S. Indication and Prognostic Significance of Conversion Surgery in Patients with Liver Metastasis from Gastric Cancer. Oncology. 2020 Feb 14:1-7.

14. Chan DY, Syn NL, Yap R, Phua JN, Soh TI, Chee CE, Nga ME, Shabbir A, So JB, Yong WP. Conversion Surgery Post-Intraperitoneal Paclitaxel and Systemic Chemotherapy for Gastric Cancer Carcinomatosis Peritonei. Are We Ready? J Gastrointest Surg. 2017;21:425-

15. Nakamura M, Ojima T, Nakamori M, Katsuda M, Tsuji T, Hayata K, Kato T, Yamaue H. Conversion Surgery for Gastric Cancer with Peritoneal Metastasis Based on the Diagnosis of Second-Look Staging Laparoscopy. J Gastrointest Surg. 2019;23:1758-

16. Yasufuku I, Nunobe S, Ida S, Kumagai K, Ohashi M, Hiki N, Sano T. Conversion therapy for peritoneal lavage cytology-positive type 4 and large type 3 gastric cancer patients selected as candidates for R0 resection by diagnostic staging laparoscopy. Gastric Cancer. 2020;23:319-

17. Eisenhauer EA, Therasse P, Bogaerts J, Schwartz LH, Sargent D, Ford R, Dancey J, Arbuck S, Gwyther S, Mooney M, Rubinstein L, Shankar L, Dodd L, Kaplan R, Lacombe D, Verweij J. New response evaluation criteria in solid tumours: revised RECIST guideline (version 1.1). Eur J Cancer. 2009;45:228-

18. Ishigami H, Fujiwara Y, Fukushima R, Nashimoto A, Yabusaki H, Imano M, Imamoto H, Kodera Y, Uenosono Y, Amagai K, Kadowaki S, Miwa H, Yamaguchi H, Yamaguchi T, Miyaji T, Kitayama J. Phase III Trial Comparing Intraperitoneal and Intravenous Paclitaxel Plus S-1 Versus Cisplatin Plus S-1 in Patients With Gastric Cancer With Peritoneal Metastasis: PHOENIX-GC Trial. J Clin Oncol. 2018;36:1922-

19. Kinoshita J, Fushida S, Tsukada T, Oyama K, Okamoto K, Makino I, Nakamura K, Miyashita T, Tajima H, Takamura H, Ninomiya I, Ohta T. Efficacy of conversion gastrectomy following docetaxel, cisplatin, and S-1 therapy in potentially resectable stage IV gastric cancer. Eur J Surg Oncol. 2015;41:1354-

20. Fukuchi M, Ishiguro T, Ogata K, Suzuki O, Kumagai Y, Ishibashi K, Ishida H, Kuwano H, Mochiki E. Prognostic Role of Conversion Surgery for Unresectable Gastric Cancer. Ann Surg Oncol. 2015;22:3618-

21. Choe HJ, Kim JW, Han SH, Lee JH, Ahn SH, Park DJ, Kim JW, Kim YJ, Lee HS, Kim JH, Kim HH, Lee KW. Conversion Surgery in Metastatic Gastric Cancer and Cancer Dormancy as a Prognostic Biomarker. Cancers (Basel). 2019;12:pii: E86. doi: 10.3390/cancers12010086.

22. Solaini L, Ministrini S, Bencivenga M, D'Ignazio A, Marino E, Cipollari C, Molteni B, Mura G, Marrelli D, Graziosi L, Roviello F, De Manzoni G, Tiberio GAM, Morgagni P. Conversion gastrectomy for stage IV unresectable gastric cancer: a GIRCG retrospective cohort study. Gastric Cancer. 2019;22:1285-

\section{Figures}




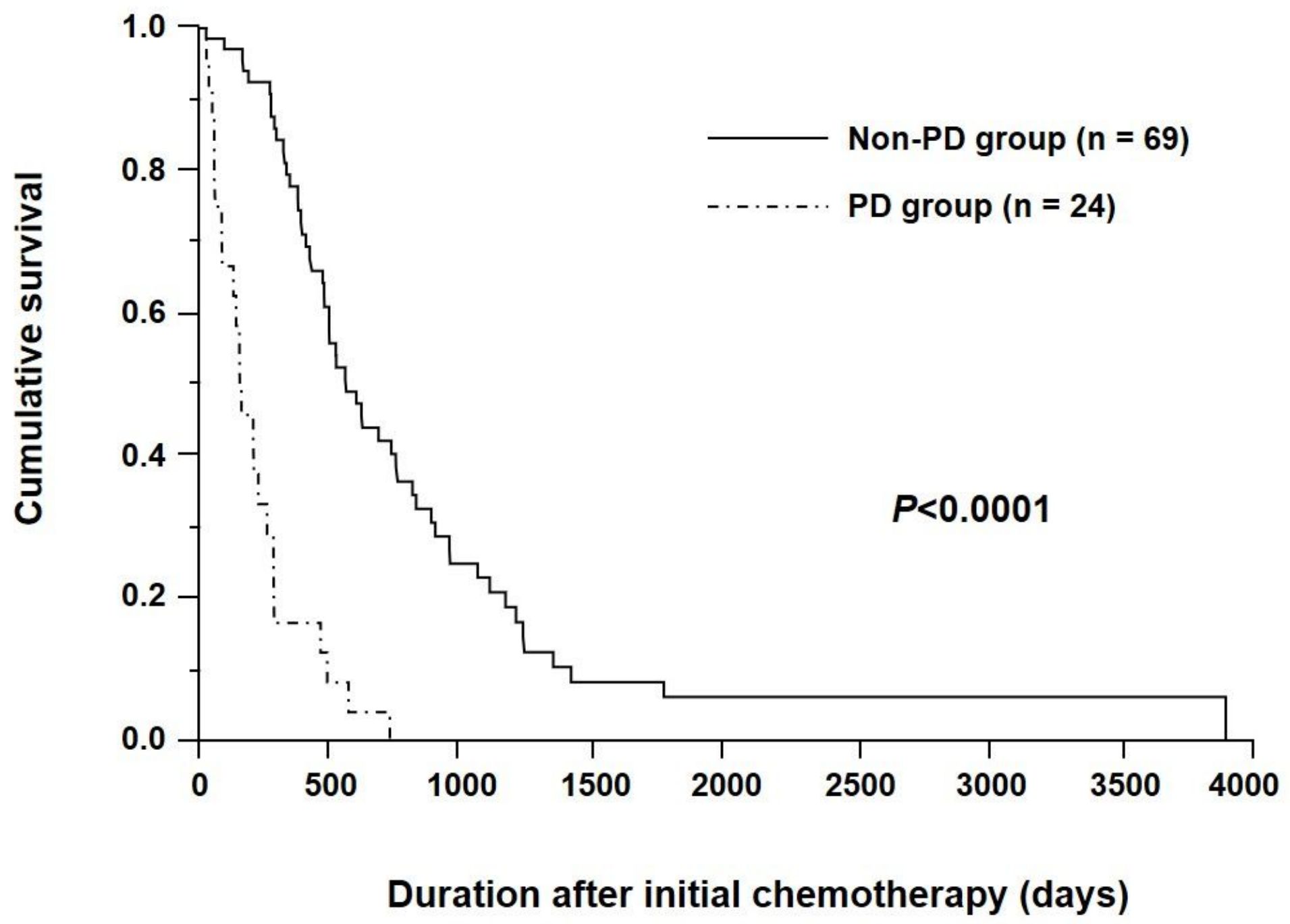

Figure 1

Kaplan-Meier survival curves according to tumor response. Patients with progressive disease (PD) had significantly poorer survival than those with non-PD $(p<0.0001)$. 


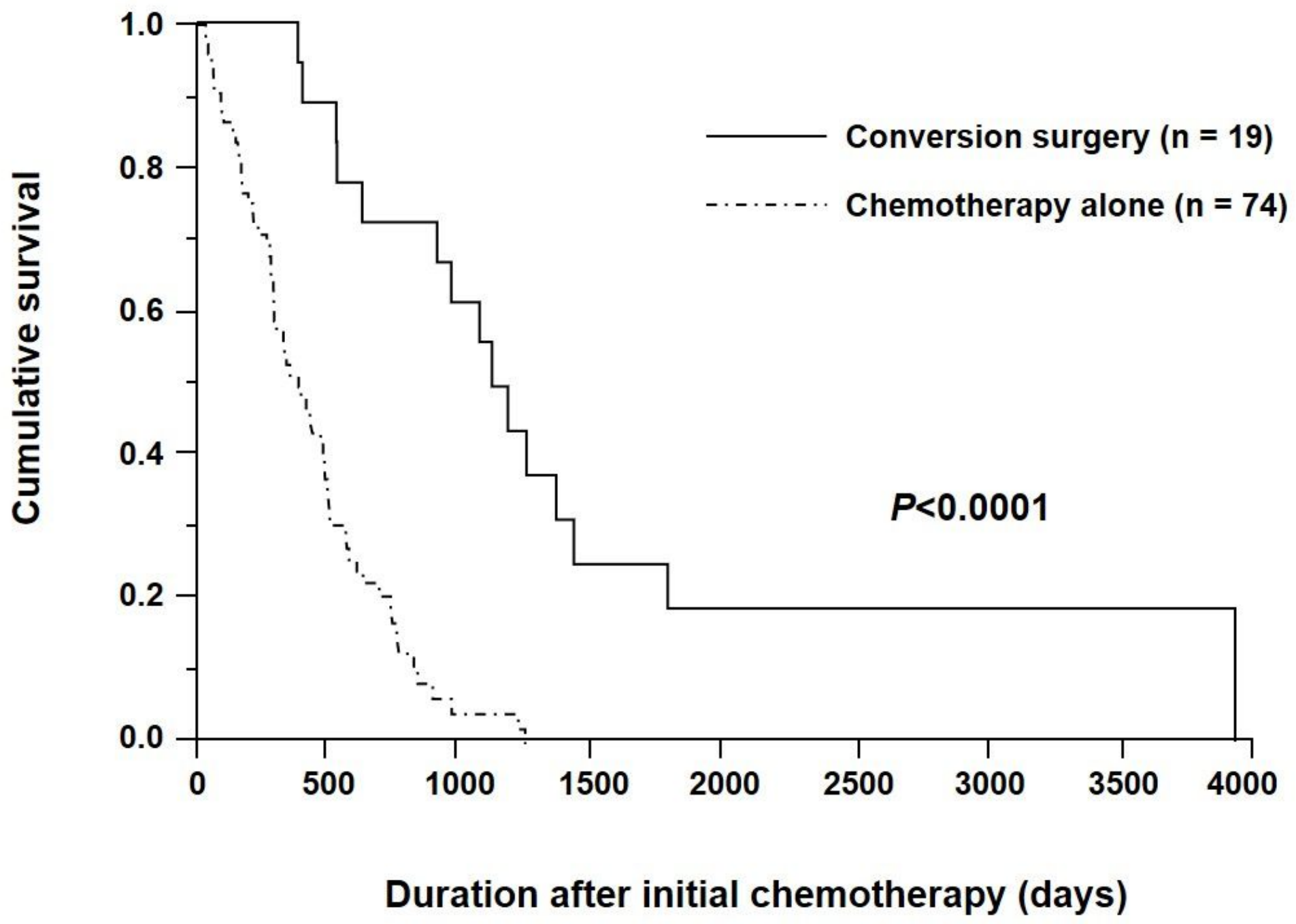

Figure 2

Kaplan-Meier survival curves according to surgical intervention $(n=93)$. Patients who underwent conversion surgery had significantly better survival than those who underwent chemotherapy alone $(p<0.0001)$. 


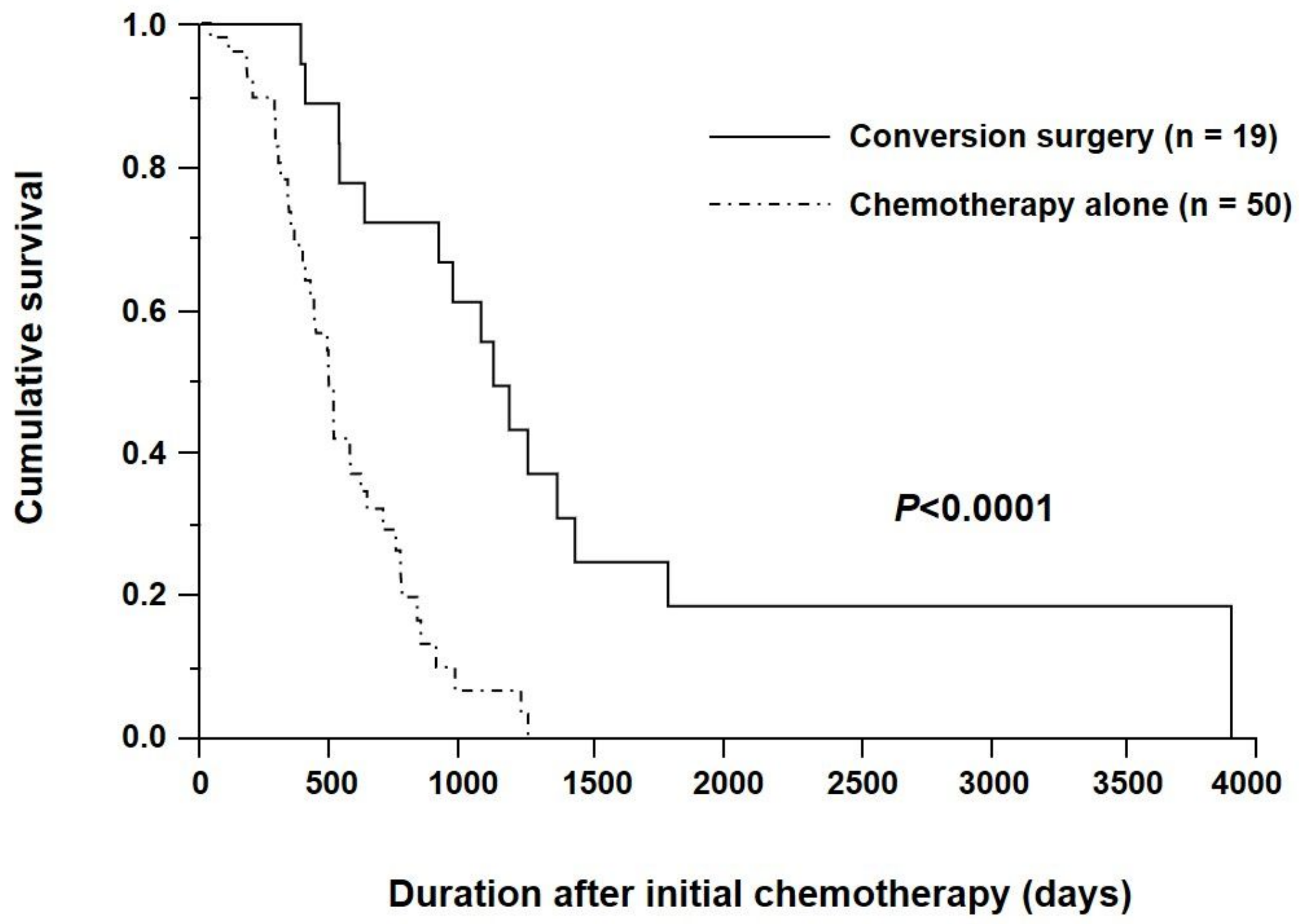

Figure 3

Kaplan-Meier survival curves according to surgical intervention in the non-PD (progressive disease) group $(\mathrm{n}=$ 69). Among patients with non-PD, those who underwent conversion surgery had significantly better survival than those who underwent chemotherapy alone $(p<0.0001)$. 